\title{
ISLAM DAN KEHARMONIAN KAUM DI SINGAPURA
}

\author{
Saifuddin Amin \\ Muhammadiyah Islamic College, Singapura \\ saifuddinamin@gmail.com
}

\begin{abstract}
This Paper aims to find out on the response of Singapore as a multi-racial country and religion towards the Muslims and its role in taking care of its racial harmony in Singapore. This mix of methods of qualitative and quantitative through the approach of direct observation has found that the government of Singapore gave a good attention for Islam. This happens in such ways that the law named AMLA and muslims in Singapore take part in keeping the racial harmony in many ways such as involving in IRO organization, choosing An-Nadhah mosques as a racial harmony centre, encouraging the dialogues between religion and the muslims. Most important role in MUIS is as official instituion to have such harmony by having seminars and khutbah as well as application of downloaded information in curriculum development based on racial harmony. As the result, it is hopeful to let this be as a research for other countries that has a different system that is similar to Singapore for the sake of a better harmony.
\end{abstract}

Key words : Islam, Muslim, Singapore, Harmony

\begin{abstract}
Abstrak
Penelitian ini bertujuan untuk mengetahui keadaan Singapura sebagai negara multirasial dan agama terhadap umat Islam dan perannya dalam menjaga harmoni masyarakat di Singapura. Penelitian ini menggunakan metode kualitatif dan kuantitatif melalui pendekatan pengamatan langsung, penelitian ini telah menemukan bahwa pemerintah Singapura memberikan perhatian yang baik untuk Islam. Hal ini pemerintah singapura membantu pembentukan lembaga hukum ke Islaman bernama AMLA dan muslim di Singapura mengambil bagian dalam menjaga keharmonisan masyarakat dalam banyak hal seperti terlibat dalam organisasi IRO, memilih masjid An-Nadhah sebagai pusat harmonisasi masyarakat, mendorong dialog antara agama dan kaum muslimin. Peran terpenting dalam MUIS adalah sebagai lembaga resmi untuk memiliki keharmonisan seperti itu dengan mengadakan seminar dan khotbah serta penerapan informasi yang bisa diambi di websaite sebagai pelengkap dalam pengembangan kurikulum berdasarkan pada harmonisasi. Sebagai hasilnya, kami berharap ini menjadi penelitian bagi negara lain yang memiliki sistem berbeda yang mirip dengan Singapura demi menjaga harmonisasi yang lebih baik.
\end{abstract}

Kata kunci: Islam, Muslim, Singapura, Harmoni

\section{Pendahuluan}

Singapura adalah sebuah Negara kepulauan dan Negara kota Asia tenggara yang terletak di penghujung Semenanjung Malaysia, berbatasan dengan Johor (Malaysia) dan kepulauan Riau Batam (Indonesia). Terletak 137 kilometer dari Khatulistiwa.

Luas Negara Singapura $682 \mathrm{~km}^{2}$ dengan penduduk berjumlah 3.771 .700 menurut sensus penduduk yang diadakan pada tahun 2010. ${ }^{1}$ Singapura merdeka

${ }^{1}$ http://www.singstat.gov.sg/pubn/reference/yosll/statsT-demography.pdf. $26 / 10 / 2010$ 
pada tanggal 9 Agustus tahun 1965, setelah berpisah dari Malaysia. Dalam Perjalanan sejarahnya, Singapura mempunyai peranan penting dalam penyebaran islam di Asia Tenggara. Posisi strategis yang dimiliki Singapura saat itu adalah dikarenan Singapura menjadi tempat transit bagi perdagangan dari berbagai kawasan yang ada di dunia. Pada sisi lain, letak yang strategis ini juga sangat strategis untuk menjadikan Singapura sebagai pusat informasi dan komunikasi dakwah islam, baik pada Kesultanan Malaka sebelum kedatangan kolonial Eropa, sampai pada abad ke 20.

Saat ini Singapura telah menjelma menjadi salah satu negara yang terkuat dalam bidang ekonomi di Asia Tenggara. Bahkan menurut laporan yang dikeluarkan oleh Worldwide Cost of living survey pada bulan april 2017 lalu, menyebutkan bahwa Singapura bukan saja negara dengan kekuatan ekonomi yang diperhitungkan di dunia, bahkan telah menjadi kota yang termahal di dunia, menggeser Hongkong yang selama ini memegang rekor tersebut.

Muslim Singapura secara politis tergolong minoritas yang hidup di tengah masyarakat pluraldan multi-kultural. ${ }^{2}$ Sejak kolonialisasi Inggris, keragaman etnis, budaya, danagama semakin tampak jelas di negara ini sebagaikonsekuensi dari lajunya arus migrasi terutamadari etnis Cina. ${ }^{3}$ Selain itu, arusmodernisasi dan pembangunan yang begitu pesatserta ekonomi global modern yang berlangsung dinegara ini memerlukan tenaga kerja yang handal danprofesional di bidangnya.Hal ini menjadi salah satufaktor penyebab lajunya arus migrasi tenaga kerjadari berbagai belahan dunia ke negara ini, sehinggasemakin menambah keragaman etnis, budaya, danagama (pluralitas dan multikultural) warga Singapura.

Pencapaian Singapura yang begitu hebat tak lepas dari peranan masyarakat yang berbilang kaum dan bangsa serta agama dalam mewujudkan keharmonian kaum dikalangan masyarakat yang ikut berperan dalam mewujudkan cita-cita pemerintahannya. Hal inilah yang menjadi salah satu faktor kemajuan tersebut yaitu wujudnya keharmonian antar kaum dan agama di dalam masyarakat Singapura

Pemerintah Singapura menyadari bahwa setiap masyarakat dalam membina peradaban pasti perlu menitikberatkan kepada keharmonian kaum.Hal ini merupakan faktor utama dalam membina peradaban dalam masyarakat. Sehubungan dengan itu, kita dapat melihat pada zaman moden ini, pemerintah akan terus memastikan wujudnya keharmonian diperingkat nasional bahkan internasional serta memastikan bahwa keharmonian kaum akan kekal terpelihara.

Bahkan di zaman globalisasiseperti sekarang ini, kita tidak bisa lagi hidup terpisah atau terasing di negara masing- masing. Malahan seluruh dunia Number 3. 2004

2 Suzaina Kadir, "Islam, State, and Society in Singapore".Inter-Asia Cultural Studies.Vol. 5

${ }^{3}$ Hefner, Robert W. (ed.). The Politics of Multiculturalism, Pluralism and Citizenship in Malaysia, Singapore, and Indonesia. Honolulu: University of Hawai. (2001) 
sekarang ini seakan-akan merupakan sebuah kampung yang luas, saling berhubung antara satu dengan yang lainnya berinteraksi tanpa ada batas. Maka kondisi kestabilan sebuah negara mungkin juga bergantung kepada situasi negara lain yang berada di sekitar negara tersebut.Di sinilah keharmonian kaum memiliki peranan yang sangat sentral dalam mewujudkan kemajuan sebuah negara, karena hanya dengan kestabilan sebuah negara yang dapat mewujudkan kemajuan negara tersebut.

Dalam makalah ini kami akan mencoba mendeskripsikan tentang peranan Islam di Singapura dalam menjaga keharmonian kaum di negara yang berbilang kaum dan bangsa yang bernama singapura.

\section{Islam di Singapura}

Berdasarkan sensus penduduk yang di keluarkan oleh jabatan statistic Singapura, islam merupakan agama yang minoritas di kalangan masyarakat Singapura, hal ini dapat kita lihat pada tabel berikut ini :

Tabel 1: persentase pemeluk agama di Singapura berdasarkan sensus penduduk tahun 2010

\begin{tabular}{|c|l|c|c|}
\hline \multirow{2}{*}{ No } & \multirow{2}{*}{ Pemeluk Agama } & 2000 & 2010 \\
\cline { 3 - 4 } & Kristen & 14,6 & 18,3 \\
\hline 2 & Budha & 42,5 & 33,3 \\
\hline 3 & Taois & 8,5 & 10,9 \\
\hline 4 & Islam & 14,7 & 14,9 \\
\hline 5 & Hindu & 4,0 & 5,1 \\
\hline 6 & Tanpa agama & 14,8 & 17,0 \\
\hline 7 & Lain- lain & 0,6 & 0,7 \\
\hline
\end{tabular}

Sumber : Department of Statistics, Ministry of Trade $\mathcal{E}$ Industry, Republic of Singapore, 2010,Census of Population 2010 Statistical Release 1 Demographic Characteristics, Education, Language and Religion, Singapore

\begin{tabular}{|l|l|r|r|r|r|r|c|}
\hline No & Etnik & \multicolumn{2}{|c|}{ Jumlah penduduk Singapura } & \multicolumn{3}{|c|}{ Persentase } \\
\cline { 3 - 8 } & & 1990 & 2000 & 2010 & 1990 & 2000 & 2010 \\
\hline 1 & Cina & 2.127 .900 & 2.513 .800 & 2.794 .000 & 77,8 & 76,8 & 74,1 \\
\hline 2 & Melayu & 384.300 & 455.200 & 503.900 & 14.0 & 13,9 & 13,4 \\
\hline 3 & India & 190.000 & 257.900 & 348.100 & 7,1 & 7,9 & 9,2 \\
\hline 4 & Lain- lain & 29.600 & 46.400 & 125.800 & 1,1 & 1,4 & 3,3 \\
\hline
\end{tabular}

Tabel 2 : Persentase penduduk Singapura berdasarkan etnik Sumber : Department of Statistics, Ministry of Trade E Industry, Republic of Singapore, 2010,Census of Population 2010 Statistical Release 1 Demographic Characteristics, Education, Language and Religion, Singapore 
Dari statistik diatas dapat kita simpulkan bahwa Islam di Singapura hanya sekitar 14,9 \% dan melayu merupakan etnis yang paling banyak memeluk agama Islam, sehingga sangat identik slogan yang menyatakan melayu adalah Islam, dan selebihnya berasal dari etnis yang lain.

Sebagai minoritas di sebuah negara yang maju dan menganut sistem sekuler baik dalam pemerintahan maupun dalam sistem pendidikan, yang secara umumnya sistem sekuler merupakan sistem yang biasanya memisahkan antara agama dengan urusan yang lainnya, namun muslim Singapura tetap berusaha untuk mengekalkan identitas mereka sebagai seorang muslim dan juga sebagi seorang melayu. Akan tetapi muslim Singapura berhadapan dengan sebuah cabaran yang sangat besar ketika banyak peristiwa yang terjadi memberi kesan negatif terhadap Islam, dan kaum muslimin, khususnya setelah kejadian 11 september. Hal ini meninggalkan kesan, dimana pemerintah Singapura memperhatikan perkembangan Islam di Singapura lebih intens dan waspada. Menurut Husin Mutalib dalam bukunya Melayu Singapura menyatakan bahwa sikap waspada yang lebih besar dari pemerintah terhadap orang melayu menjadi lebih berat dengan wujudnya kedudukan atau pandangan yang berbeda antara pemerintah dengan muslim Singapura dibeberapa isu yang berkembang. Sebagai contoh, muslim Singapura mengutuk keras serangan Amerika Serikat ke Afghanistan pada tahun 2001 dan juga serangan ke Irak pada tahun 2003.

Sistem sekuler yang selama ini dianut oleh Singapura memang mempunyai implikasi yang nyata dalam pengamalan agama.Misalnya, suara azanyang berfungsi sebagai pengingat dan pemanggilMuslim untuk mendirikan shalat, tidak bolehdikumandangkan melalui pembesar suara.Alasannyaadalah agar non-Muslim yang mayoritas tidakterganggu. Contoh lain dapat ditunjukkan daripelarangan memakai jilbab bagi siswi Muslim disekolah-sekolah pemerintah. Seperti ditegaskanoleh, PM, Lee Hsien Loong, kepada wargaMuslim; "Hijab was not part of the school uniforms and effectively banned in institutions oflearning. Saat diwawancarai oleh Berita Harian,Malay Newspaper, putra Lee Kuan Yew itukembali menegaskan bahwa pelarangan jilbabdimaksudkan untuk memelihara integrasi dankeharmonian sosial.Jilbab dipandang sebagaisimbol agama tertentu. Mengizinkan Muslimahmemakai jilbab di sekolah akan menggangguintegrasi nasional, karena akan memunculkanpersoalan di kalangan siswa lainnya. Laranganyang sama juga dulu pernah diberlakukan kepadapara pegawai Muslimah saat mereka bekerja dilembaga-lembaga pemerintah seperti rumah sakit,klinik dan sebagainya.(Helmiati, 2013 : 88). Dan larangan pemakaian simbol-simbol keagamaan bukan hanya dikhususkan untuk Islam saja, tetapi pelarangan ini juga berlaku untuk agama yang lain.

Dalam bidang pendidikan, walaupun Singapura menganut sstem Sekuler, yang tidak mengizinkan untuk mengadakan pembelajaran agama di sekolah- sekolah umum, namun sistem madrasah yang merupakan ciri khas pendidikan Islam masih wujud di Singapura sampai saat ini. Sedikitnya ada 
enam madrasah yang diakui oleh pemerintah Singapura ditambah beberapa institusi pengajian tinggi memainkan peranan yang sangat besar dalam menyediakan pendidikan agama dan akhlak bagi peserta didik. Dan pada masa yang sama, pemerintah Singapura tetap memberikan ruang yang luas untuk mengajarkan agama di madrasah- madrasah yang diadakan di masjid - masjid dan persatuan- persatuan Islam di Singapura.

Keenam madrasah itu adalah Madrasah Al-Irsyad Al-Islamiah, Madrasah Al-Maarif Al-Islamiah, Madrasah Alsagoff Al-Islamiah, Madrasah Aljunied AlIslamiah, Madrasah Al-Arabiah Al-Islamiah, dan Madrasah Wak Tanjong AlIslamiah.

Pembatasan jumlah madrasah di Singapura disebabkan Pemerintah Singapura berpendapat bahwa enam madrasah tersebut telah cukup untuk memelihara dan menyiapkan kader-kader muslim Singapura. Selebihnya, para siswa muslim harus bergabung dengan siswa lainnya di sekolah-sekolah umum yang dimiliki pemerintah. Tahun 2007 upaya "membatasi" jumlah madrasah dilakukan kembali oleh pemerintah (melalui MUIS4 sebagai Pembina pendidikan Islam) dengan membuat program Joint Madrasah System (JMS) ${ }^{5}$ yang pada tahap awal melibatkan tiga madrasah, yaitu Madrasah Aljunied, Madrasah Al'Arabiah, dan Madrasah al-Irsyad. Melalui program ini, kewenangan ketiga madrasah tersebut dalam menyelenggarakan pendidikan semakin terbatas.

Madrasah Aljunied dan Al-'Arabiah dibatasi pada madrasah tingkat menengah, sedangkan Madrasah Al-Irsyad khusus menyelenggarakan madrasah tingkat rendah. Dengan pembahagian demikian, maka sejak tahun pelajaran 2009, Madrasah Al-Junied dan Al-'Arabiah tidak lagi menerima calon siswa tingkat rendah dan hanya menerima calon tingkat menengah. Begitu juga dengan Madrasah Al-Irsyad, mulai tahun yang sama hanya menerima calon siswa tingkat rendah. Dengan kebijakan ini, maka jumlah jenjang pendidikan madrasah menjadi berkurang, tentu saja hal ini berdampak pada berkurangnya kesempatan anak-anak muslim di Singapura mengikuti pendidikan di madrasah.

Terbatasnya jumlah madrasah dan calon siswa yang diterima mengakibatkan banyak siswa muslim yang terpaksa harus melanjutkan ke sekolah umum. Padahal animo masyarakat muslim Singapura untuk memasukkan putra-putrinya ke madrasah semakin tinggi seiring meningkatnya tingkat religiusitas dalam masyarakat. Hal ini, misalnya, terlihat dari jumlah pendaftar ke Madrasah Aljunied yang mencapai 800 siswa pada tahun 2000 dan

4 Majlis Ugama Islam Singapura (MUIS) adalah sebuah badan berkanun di Singapura yang ditubuhkan pada tahun 1968 ketika Akta Undang-undang Pentadbiran Islam (KLSM) dikuatkuasakan. Peranannya adalah untuk menjaga kepentingan komuniti Muslim Singapura. Ia berada di bawah Kementerian Pembangunan Masyarakat, Belia dan Sukan, dan di bawah kawalanlangsungMenteri Hal Ehwal Ugama Islam.http://ms.wikipedia.org/wiki/Majlis_Ugama_Islam_Singapura, diakses 26 Maret 2015.

5 Joint Madrasah System (JMS) Gabungan Sistem Madrasah- diperkenalkan pada tahun 2008 untuk membantu madrasah-madrasah di Singapura meningkatkan mutu kualiti dalam sistem madrasah. http://madrasah.sg/News/index.html. 
meningkat menjadi 1000 di tahun 2004. Padahal Madrasah Aljunied hanya akan menerima 200 siswa setiap tahunnya. ${ }^{6}$

Di samping keenam madrasah tersebut, juga terdapat institusi pengajian tinggi atau perguruan tinggi Islam sebagai lanjutan bagi peserta didik untuk medapatkan pendidikan agama yang lebih tinggi.Diantara perguruan tinggi Islam di Singapura saat ini adalah Muhammadiyah Islamic College, Az- Zuhri, Andalus dan Pergas.

Dengan cabaran- cabaran di atas, tidak lantas menjadikan Singapura sebagai negara yang tidak mesra terhadap Islam.Banyak keunikan yang ditemui berkenaan dengan hubungan pemerintah dengan Islam sebagai agama minoritas di negara ini. Sehingga tidak berlebihan kalau penulis meminjam istilah Husin Mutalib dalam sebuah seminarnya di kuala lumpur bahwa minoritas muslim Singapura adalah minoritas yang paling bahagia.

Bermula dengan dibentuknya AMLA (Administration Of Muslim Law Act) pada tahun 1966, yang berfungsi sebagai undang- undang yang mengatur hal ihwal masyarakat Islam di Singapura, sistem perundangan Islam di Singapura dapat terarah dan terpandu. Dalam hal ini AMLA sebagai undang- undang mempunyai peranan yang terbatas dan mempunyai peran dalam tiga bidang :

1. Pengurusan hal ehwal keagamaan Islam seperti bidang kuasa Majlis Ugama Islam Singapura (MUIS), pengurusan masjid dan sekolah agama (Madrasah) di Singapura, pengurusan sumber kewangan (Pengurusan wang Zakat, harta dan hartanah Waqaf, Nazar dan Wasiat) sijil halal dan pengurusan haji, serta urusan pendaftaran Kemasukan Agama Islam.

2. Hal ehwal kekeluargaan Islam seperti bidang kuasa Mahkamah Syariah, perkahwinan dan peceraian, serta kehartaan.

3. Lain-lain perkara yang terkandung dalam akta ini seperti kedudukan Pendaftar, Kadi dan Naib Kadi sebagai pegawai pemerintah, saksi dalam perbicaraan, bukti dalam perbicaraan, peraturan yang dikemukakan oleh Pemerintah Singapura dan hukuman terhadap kesalahan kesalahan di bawah akta ini.(Administration of Muslim Law Act Cap. 3)

Untuk memudahkan pelaksanaan undang- undang tersebut, maka dibentuklah badan yang memastikan pelaksanaan undang- undang tersebut. Ketiga badan tersebut adalah Majlis Ugama Islam Singapura (MUIS), Pejabat Nikah (Registry of Muslim Marriages-ROMM) dan Mahkamah Syariah. Badanbadan ini ditentukan bidang kuasanya yang tersendiri dalam pelaksanaan hukum Islam di Singapura.

MUIS mempunyai peranan yang sangat besar dalam pelaksanaan hukum Islam di Singapura. Diantara tugas-tugas yang menjadi bidang kerja MUIS adalah:

${ }^{6}$ Mohamad Yusof Bin Sa'ad, pengembangan kurikulum pendidikan agama Islam di Singapura (Studi kasus madrasah Al juneid al-islamiah) Disertasi, UMM Malang, 2016, h. 5 
1. Memberi saran kepada presiden Singapura dalam masalah-masalah yangberkaitan dengan agama Islam di Singapura.

2. Mengurusi masalah yang berkaitan dengan agama Islam dan kaum muslimin di Singapura, termasuk urusan haji dan sertifikasi halal

3. Mengelola wakaf dan dana kaum muslimin berdasarkan undang-undang dan amanah

4. Mengelola pengumpulan zakat, infak, dan sedekah, untuk mendukung dan mensyiarkan agama Islam atau untuk kepentingan umat Islam

5. Mengelola semua masjid dan madrasah di Singapura

6. Untuk melaksanakan fungsi dan tugas lainnya yang diberikan kepada Majlis berdasarkan Undang-undang atau hukum tertulis lainnya. (Administration of Muslim Law Act Cap. 3 part II)

7. Mengeluarkan Fatwa (www.muis.gov.sg)

Hal unik lainnya adalah adanya Kementerian khusus yang menangani masalah hal ihwal masyarakat Islam Singapura, yang tidak ditemukan pada agama yang lain. Saat ini kementrian tersebut dipimpin oleh Dr Yacob Ibrahim.Dan juga adanya Mufti yang dipilih melalui persetujuan Presiden Singapura dan juga dilantik oleh Presiden Singapura. Fatwa yang dikeluarkan oleh kantor mufti akan menjadi sebuah produk hukum yang wajib ditaati oleh masyarakat Islam Singapura.

Banyak pencapaian yang telah dicapai oleh MUIS sebagai salah satu lembaga pemerintah yang tugaskan untuk hal ihwal masyarakat Islam Singapura.Salah satu contoh nyata dalam hal ini adalah manajemen masjid yang sangat baik dimana Masjid memiliki programterencana yang dibina.Tidak seperti yang dipahamiselama ini, bahwa masjid hanya sebatas tempat ibadah saja. Di Singapura, masjid benar-benar berfungsisebagaimana zaman Rasulullah, yaitu sebagai pusatkegiatan Islam yang diarahkan tidak hanya untukaktivitas ibadah seperti shalat, baca al-Qur'an, danwirid pengajian, tetapi juga berfungsi sebagai sentralpendidikan dan pembangunan sosial umat.Masjid di Singapura pada umumnya tidak hanyamemiliki ruang tempat shalat saja, tetapi dilengkapidengan berbagai fasilitas untuk keperluan jemaah.Diruas kanan dan kiri setiap masjid terdapat ruanganruangankelas untuk belajar agama dan kursusketerampilan. Selain itu, juga terdapat fasilitaslainnya seperti ruang kantor administrasi atausekretariat pengelolaan masjid, ruang sidang, ruangserba guna atau auditorium, ruang kelas untuk belajar,perpustakaan, kamar jenazah serta ruang untukaktivitas dan program pembangunan sosial umat. $^{7}$

Dalam pengelolaan zakat, MUIS sendiri sebagai lembaga tertinggipemerintah untuk urusan agama Islam bertanggungjawab dan terlibat

7 Mohamed Ali Atan. "Pengurusan Masjid: Pengalaman Republik Singapura". Kertas kerja Konvensyen Masjid 2005.Anjuran Majlis Ugama Islam Singapura (MUIS), Singapura.2-3 Ogos.MUIS. New Generation Mosque In Singapore and Their Activities, 2005), h. 2 
langsung dalam pengelolaan Zakat, Infaq dan Shadaqoh, beserta wakaf, sehingga MUIS dapat mengetahu pengelolaannya. Saat ini, pengelolaan zakat dilakukan dengan cara online melalui sistem perbankan yang ada di Singapura. Bahkan MUIS telah mendapat persetujuan dari pemerintah untuk menarik sumbangan wajib dari seluruh pekerja muslim setiap bulannya, untuk pembangunan masjid dan madrasah yang disebut dengan Mosque and Madrasah Building Fund. Dengan pengelolaan dana yang besar ini, masjid di Singapura dapat dikelola dengan baik dengan manajemen yang modern.

\section{Peran Islam Dalam Keharmonian Kaum Di Singapura}

Keberagaman dalam agama dan strata sosial merupakan sunnatullah yang tidak bisa kita elakkan dalam kehidupan ini.Dasar filsafatnya ialah bahwa manusia diciptakan dalam perbedaan dan makhluk sosial. Manusia terlahir sebagai makhluk yang memiliki keunikan dengan segala perbedaan yang ada. Setiap anak yang dilahirkan dalam satu keluarga pasti memiliki perbedaan tersendiri, walaupun ia berasal dari dua orang yang sama ayah dan ibu namun kelak ketika tumbuh anak akan memiliki karakteristik yang berbeda, entah dengan ayah dan ibunya ataupun saudara-saudaranya. Lebih luas lagi, ketika keluar dari faktor persamaan keluarga, akan didapati perbedaan-perbedaan yang nampak mencolok. Tidak akan pernah ada seorangpun yang mampu menyeragamkan manusia di dunia ini, dalam hal apapun.

Perbedaan adalah rahmat yang diturunkan Tuhan, yang akan mewarnai kehidupan dunia agar menjadi menarik. Apa jadinya ketika Tuhan hanya menciptakan manusia ini seragam, sama semua, hitam semua, putih semua, Tuhan menciptakan satu warna. Tak ayal nilai estetika dari sebuah perbedaanpun tidak akan muncul, warna pelangi tak seindah yang kita lihat, kehidupan dunia begitu monoton.

Begitu juga dalam kehidupan social kemasyarakatan.Kepelbagian dalam masyarakat adalah suatu kemestian yang wajib diterima sebagai sebuah anugerah dari Allah SWT.Hal inilah yang perlu menjadi landasan berfikir dalam mewujudkan keharmonian kaum dan agama dalam sebuah masyarakat.

Perdana Menteri Lee Hsien Loong dalam sambutannya pada Hari Keharmonian Kaum yang jatuh pada setiap tanggal 21 Juli menyatakan bahwa Salah satu prinsip asas bagi Singapura adalah keharmonian antara pelbagai kaum dan agama. Karena itu,rakyat Singapura seharusnya meraikan kepelbagaian dalam negara dan saling mengongsi dan menghormati adat resam dan budaya antara satu sama lain. (Berita Harian, Media Corp, PM Lee: Keharmonian Pelbagai Kaum, Agama Adalah Prinsip Asas S'pura, tanggal 21 juli, 2017)

Tak dapat dipungkiri bahwa perbedaanperbedaanini-termasuk perbedaan agama-menjadisalah satu pembatas antar warga dalam kehidupansosial. Sebagai contoh sederhana, Muslim misalnyatidak akan makan di restoran China yang 
non-Muslimkarena khawatir terkontaminasi oleh babi dan zat-zat lain yang haram dalam pandangan Islam.

Namun demikian, dalam konteks Singapura, Muslim yang hidup di tengah-tengah masyarakatyang sekular dan multikultural, sampai tahaptahaptertentu nampak mampu beradaptasi dan berintegrasi dengan seluruh lapisan masyarakat.Salah satu contohmenarik adalah sikap Muslim pada acara jamuanmakan dengan rekan-rekan sewarganya yang non-Muslim. Mengingat jumlah Muslim hanya 15\%dari seluruh jumlah penduduk, maka jamuan makanbersama dengan rekan-rekannya yang non-Muslimmenjadi sesuatu yang sulit dielakkan. ${ }^{8}$

Begitu pula sebaliknya, ketika bulan Ramadhan tiba, dan juga hari Raya Idul fitri, banyak kita lihat pemeluk agama lain bersama- sama dengan kaum mulismin melaksanakan buka puasa bersama dan bahkan saling silaturahmi antara satu dengan yang lainnya, walaupun mereka berbeda agama dan ras.

Walaupun kadang jamuan makan bersama dengan teman- teman yang non muslim kadang menyisakan permasalahan dan menempatkan seorang muslim dalam keadaan yang serba susah.Mengingat Islammengatur tentang makanan yang halal dan haramuntuk dikonsumsi seperti khamar, anjing, babi, darah,dan bangkai yang diharamkan karena zatnya, juga adamakanan yang diharamkan karena suatu sebab yang bukan berkaitan dengan zatnya seperti daging hewanyang disembelih tanpa menyebut nama Allah. Maka dalam kondisi semacam itu, pertanyaannya adalah apakah muslim akan menghindari jamuan makanantar budaya tersebut, dan sikap apa yang merekaambil dalam kondisi semacam itu? atau mereka mengatur strategi sehingga dapat beradaptasi dengansituasi dan kondisi di mana mereka berada tanpa melanggar ajaran agama?

Tetapi hal itu semua tidak menjadikan muslim Singapura tidak mampu memberikan kontribusi yang nyata dalam menjaga keharmonian kaum yang menjadi salah satu keistimewaan yang dapat ditemukan di Negara ini.

Walau bagaimanapun, muslim di Singapura telah memberikan sebuah pembelajaran yang sangat berharga tentang bagaimana seseorang tetap menjaga iman dan ajarannya tanpa melukai perasaan orang lain. Hal initerindikasi dari sikap dan pemikiran yang memberitempat bagi kehadiran bangsa dan agama laindalam pergaulanpublik, adanya sikap toleran, saling menghargai,saling membantu, dan kemampuan bekerjasama dengan sesama.

Dalam contoh lain di mana azan tidak diperbolehkan menggunakan pengeras suaramisalnya,sikap mereka adalah menerima kebijakan tersebutdan sebagai solusinya azan diperdengarkan melaluiradio. Penerimaan semacam ini merupakan wujudnyata dari sikap toleran mengingat adanya masyarakat dari bangsa dan agama lainyang terganggu karena suara azan tersebut. Selain

8 Helmiati, Dinamika Islam Singapura: Menelisik Pengalaman Minoritas Muslim di Negara Singapura yang Sekular \& Multikultural, Dalam Jurnal Toleransi, vol 5, no 2 juli- desember 2013, h. 93 
itu,sikap toleran dan menghargai dari warga Muslim juga terlihat pada penerimaan mereka terhadapkebijakan pemerintah yang memindahkan komunitas Muslim yang dulu tinggal di satu kampung sehingga memungkinkan mereka untuk menjalankan agama secara berjamaah ke rumah-rumah susun yang di situterintegrasi dan terasilimilasi dengan non-Muslim.

Hal inilah yang menarik untuk dilihat dan diteliti, tentang peran serta kaum muslimin di negara Singapura dengan sistem yang sekuler dalam mewujudkan keharmonian kaum di Singapura.

Ada beberapa usaha yang dilakukan oleh kaum muslimin Singapura dalam ikut serta newujudkan keharmonian kaum di negara tersebut. Di antara usaha itu adalah :

1. Terlibat langsung dalam badan yang disahkan oleh pemerintah Singapura dalam mewujudkan keharmonian tersebut. Badan tersebut bernama IRO atau (Inter-Religious Organisation). Badan ini sebenarnya merupakan badan yang telah lama wujud di Singapura, karena didirikan pada tahun 1949, tetapi perubahan nama menjadi IRO terjadi di tahun 1961. Dalam laman resminya dinyatakan bahwa pendirian badan ini diusulkan oleh seorang ulama muslim keturunan india yang bernama Maulana Abdul Aleem Siddiqui kepada pemerintahan kolonial inggris dan akhirnya terwujud dalam suatu badan atau organisasi. Dengan berlalunya waktu IRO menyelenggarakan lebih banyak kegiatan sesuai dengan tujuannya dan berpartisipasi dalam forum lokal dan internasional untuk mempromosikan keharmonian agama di kawasan ini. Dan juga bekerjasama dengan organisasi internasional seperti The World Conference of Religions for Peace (WCRP) dan Asian Conference of Religions for Peace(ACRP).IRO juga secara berkesinambungan melakukan doa bersama dalam berbagai macam acara kenegaraandan beberapa kagiatan- kegiatan social lainnya. (iro.sg)

2. Menunjuk masjid an- Nahdhah untuk dijadikan sebagai pusat keharmonian (Harmony center) yang bertujuan untuk mengekalkan kesejahteraan dan keharmonian kaum dan agama di Singapura. Ia secara tidak langsung juga dapat mencerminkan kepada warga Singapura umumnya sifat inklusif masyarakat Islam. Ini jelas terlihat daritujuantujuan pendirian Pusat Harmoni seperti berikut ini:

a) Untuk meningkatkan kefahaman akan ajaran dan wajah Islam dan Muslim yang sebenarnya

b) Untuk menggalakkan dialog dan hubungan silang agama di setiap peringkat baik di tingkatpemimpin, masyarakat, remja dan pelajar melalui seminar, workshop, kunjungan sambil belajar dan lain-lain

c) Untuk menguatkan hubungan sosial di antara masyarakat yang multikulturil dan agama untuk membina masyarakat yang lebih bersatu padu dan berdaya tahan serta dapat menangani berbagai 
macam krisis dengan lebih rasional dan matang.Seperti dikatakan Mohamed Ali bin Atan, Kepala Pusat Harmoni Masjid An-Nahdhah, "Kalau ada orang yang ingin tahu tentang Islam di Singapura, mereka datang ke masjid ini. Banyak pengunjung Pusat Harmoni mengaku cukup belajar tentang Islam dalam 45 menit,". Sejak berdiri tahun 2006, jumlah pengunjung Pusat Harmoni sudah mencapai sedikitnya 24.533 orang dan 92 persen di antaranya adalah non-Muslim. Diantara para pengunjung non- Muslim itu adalah seorang Kristiani dari Kampong Kapor bernama Rev.Gabriel Liew. Ia yang bekunjung ke Pusat Harmoni pada 28 Agustus lalu 2011 ini menuliskan kesan positifnya tentang keberadaan Pusat Harmoni ini di buku tamu masjid. "Kami sangat terinspirasi oleh inklusivitas dan progresivitas anda pada keyakinan dan komitmen pada terciptanya kehidupan antar penganut beragam agama yang harmonis, (www.harmonycentre.sg)

3. Menggalakkan dialog antar agama dan juga antar kaum muslimin.Salah satu usaha yang digalakkan dalam rangka memelihara keharmonian kaum di Singapura adalah dengan mengadakan dialog yang berusaha untuk mengenalkan ajaran- ajaran agama yang senantiasa mengajak kepada kedamaian dan keharmonian kaum. Bahkan hal ini juga digalakkan dalam kalangan kaum muslimin secara khusus yang bertujuan untuk menyatukan dua pemahaman yang berbeda dikalangan kaum muslimin khususnya yang berkenaan dengan keharmonian kaum. Dialog ini banyak diadakan di persatuan- persatuan Islam seperti Pergas, Muhammadiyah Association, Jamiyah, dan beberapa persatuan - persatuan Islam yang lainnya. Salah satu dialog antar agama yang pernah diadakan adalah pada tanggal tahun 2015 yang dihadiri oleh beberapa ketua - ketua agama di Singapura. Dalam dialog tersebut, turut hadir Mr Sam Tan, Minister of State, Prime Minister's Office $\mathcal{E}$ Ministry of Culture, Community, And Youth, yang dilaksanakan di Singapore Islamic Hub.(www.mccy.gov.sg)

4. Peranan MUIS dalam memastikan keharmonian kaum senantiasa terjaga. Hal ini dapat kita lihat dalam beberapa usaha yang sudah dilakukan oleh MUIS diantaranya :

a. Mengadakan seminar-seminar yang bertujuan untuk memberikan pemahaman kepada kaum muslimin tentang kehidupan Rasulullah SAW yang sangat toleran dan menghormati perbedaan- perbedaan yang ada di masa Rasulullah SAW. Diantara seminar tersebut adalah seminar tentang keharmonian kaum yang menghadirkan 10 pemimpin agama di MUIS, dan sebagai pembicara dalam forum tersenut adalah Grand Mufti Singapura Mohamed Fatris Bakaram. Seminar ini dilaksanakan di Singapore Islamic Hub di Jalan Braddel Singapura. Di tahun yang sama, MUIS menghadirkan seorang cendekiawan muslim dari Amerika serikat Associate Professor dalam Bidang Islamic Studies 
Dr.Irfam Omar dengan tema "imperative Of Interfaith Dialogue : A Muslim Perspective. Seminar ini dilaksanakan di bulan Januari tahun 2013 di Mesjid An- Nahdhah sebagai pusat keharmonian kaum. Ditahun 2014, MUIS Academy mengadakan seminar yang sama dengan mengundang Grand Mufti Bosnia Harzegovina, Sheikh Dr Mustafa Ceric, dengan tajuk "Ethic and Diversity : Contribution Of Islamic Religious Leadership to the Modern World". Seminar seperti ini diadakan disetiap tahun dengan tujuan untuk mengenalkan keharmonian kaum dikalangan muslim Singapura. (MUIS Academy.)

b. Mengenalkan Islam sebagai agama Rahmatan lil'alamin dan toleransi kaum muslimin terhadap kaum yang lainnya melalui khutbahkhutbah jumat. Khutbah jumat di Singapura merupakan acara yang dikontrol langsung naskah khutbahnya oleh MUIS. Dan dalam hal ini, MUIS mempergunakan Khutbah hari Jumat sebagai sarana untuk menyebarkan risalah keagamaan, yang salah satunya adalah tentang toleransi dan keharmonian kaum.

c. Pengembangan kurikulum berbasis keharminian kaum di madrasahmadrasah di Singapura. Majlis Ugama Islam Singapura (Muis) telah meletakkan beberapa program pendidikan yang bertujuan untuk memberi pendidikan agama yang menyeluruh kepada remaja Muslim di Singapura. Pesan- pesan berkaitan dengan menghargai kepelbagaian yang wujud antara umat juga mewarnai kurikulum tersebut. Program tersebut dinamakan program a.LIVE (Living Islamic Values Everyday) yang menyediakan kepada remaja yang berumur 20 tahun ke bawah. (MUIS)

d. MUIS melalui aplikasi android ataupun app Store telah mengenalkan sebuah aplikasi dengan namaOffice Of the Mufti. Dalam aplikasi tersebut beberapa maklumat yang berkenaan dengan berbagai macam kegiatan yang berkenaan dengan Mufti dan juga fatwa dan khutbah jumat dalam tiga bahasa, Melayu, Inggris dan Tamil. Hal ini dilakukan untuk mempermudah dalam mengetahui hal- hal yang berkenaan dengan muslim di Singapura.

\section{Kesimpulan}

Dari pemaparan tentang peran umat Islam dalam rangka terlaksananya keharmonian kaum di Singapura, dapat kita simpulkan beberapa kesimpulan yaitu:

1. Sebagai kaum minoritas di Negara sekuler, Muslim Singapura menghadapi berbagai macam cabaran, baik dalam bidang ekonomi, pendidikan dan juga menjalankan syariat agamanya. Namun walau bagaimanapun, pemerintah Singapura tetap memperhatikan Islam sebagai salah satu agama yang dianut oleh mayoritas bangsa melayu yang merupakan 
penduduk pribumi di Singapura. Salah satu wujud perhatian pemerintah tersebut adalah wujudnya undang- undang yang khusus mengatur ummat Islam di Singapura yang dinamakan AMLA, dari undang- undang tersebut lahirlah tiga institusi yang mengatur hal ihwal masyarakat Islam Singapura, yaitu : MUIS, ROMM, dan juga mahkamah Syariah.

2. Peran umat Islam Singapura dalam menjaga keharmonian kaum terwujud dalam beberapa bentuk yaitu : Terlibat langsung dalam badan yang disahkan oleh pemerintah Singapura dalam mewujudkan keharmonian tersebut bernama IRO atau (Inter-Religious Organisation), Menunjuk masjid an- Nahdhah untuk dijadikan sebagai pusat keharmonian (harmony center) yang bertujuan untuk mengekalkan kesejahteraan dan keharmonian kaum dan agama di Singapura, Menggalakkan dialog antar agama dan juga antar kaum muslimin, melalui MUIS dalam bentuk Khutbah jumat, dialog dan seminar- seminar, serta mengembangkan kurikulum di madrasah berbasis keharmonian kaum.

Semoga peran umat Islam di Singapura dalam rangka mengekalkan keharmonian kaum dapat menjadi contoh bagi umat Islam di tempat lain, agar keharmonian kaum dapat senantiasa terjaga.

\section{Referensi}

AMLA, Administration of Muslim Law Act Cap. 3

Atan, Mohamed Ali. (2005). "Pengurusan Masjid: Pengalaman Republik Singapura". Kertas kerja Konvensyen Masjid 2005.Anjuran Majlis Ugama Islam Singapura (MUIS), Singapura.2-3 Ogos.MUIS. New Generation Mosque In Singapore and Their Activities.

Berita harian, media Corp, PM Lee: Keharmonian pelbagai kaum, agama adalah prinsip asas S' pura, tanggal 21 juli, 2017

Department of Statistics, Ministry of Trade \& Industry, Republic of Singapore, 2010, Census of Population 2010 Statistical Release 1 Demographic Characteristics, Education, Language and Religion, Singapore

Hefner, Robert W. (ed.). (2001). The Politics of Multiculturalism, Pluralism and Citizenship in Malaysia, Singapore, and Indonesia. Honolulu: University of Hawai.

Helmiati, Dinamika Islam Singapura: Menelisik Pengalaman Minoritas Muslim di Negara Singapura yang Sekular \& Multikultural, Dalam Jurnal Toleransi, vol 5, no 2 juli- desember 2013

Hussin Mutalib, melayu Singapura sebagai kaum minority dan muslim dalam sebuah negeri global,2015, SIRD \& NUS Press, Kuala Lumpur dan Singapore, cet 1

Mohamad Yusof Bin Sa'ad,2016, pengembangan kurikulum pendidikan agama Islam di Singapura (Studi kasus madrasah Al juneid al-islamiah) Disertasi, UMM Malang

MUIS.(2005a). Annual report 2005. Singapore: Majlis Ugama Islam Singapura.

MUIS.(2005b). Risalah Membangun Masyarakat Islam Cemerlang Singapura. Singapore:

Office of mufti, Majelis Ugama Islam Singapura(2005). Risalah for Building A Singapore Muslim Community of Excellent. second edition. Singapore: MUIS 
Suzaina Kadir. (2004). "Islam, State, and Society in Singapore".Inter-Asia Cultural Studies.Vol. 5 Number 3. 2004

www.muis.gov.sg

www.harmonycentre.sg

www.iro.sg

www.mccy.gov.sg

http://www.singstat.gov.sg/pubn/reference/yosll/statsT-demography.pdf.

http://www.straitstimes.com/ business/ economy/ singapore- ranked- worldsmost-expensive-city-for-expats-for-4th-straight-year) 